\title{
Article
}

\section{Transferrin-Decorated Niosomes with Integrated InP/ZnS Quantum Dots and Magnetic Iron Oxide Nanoparticles: Dual Targeting and Imaging of Glioma}

\author{
Didem Ag Seleci ${ }^{1,2,+}{ }^{+}$, Viktor Maurer ${ }^{1,2,+}$, Firat Baris Barlas ${ }^{3}{ }^{\circledR}$, Julian Cedric Porsiel ${ }^{1}$, Bilal Temel ${ }^{1}$, \\ Elcin Ceylan ${ }^{3}{ }^{-}$, Suna Timur ${ }^{3}$, Frank Stahl ${ }^{4}$, Thomas Scheper ${ }^{4}$ and Georg Garnweitner ${ }^{1,2, *(1)}$ \\ 1 Institute for Particle Technology (iPAT), Technische Universität Braunschweig, \\ 38104 Braunschweig, Germany; d.ag-seleci@tu-braunschweig.de (D.A.S.); \\ v.maurer@tu-braunschweig.de (V.M.); c.porsiel@tu-braunschweig.de (J.C.P.); \\ b.temel@tu-braunschweig.de (B.T.) \\ 2 Center of Pharmaceutical Engineering (PVZ), Technische Universität Braunschweig, \\ 38106 Braunschweig, Germany \\ 3 Faculty of Science Biochemistry Department, Ege University, 35100 Izmir, Turkey; \\ f.b.barlas@gmail.com (F.B.B.); elcinceylan5@gmail.com (E.C.); suna.timur@ege.edu.tr (S.T.) \\ 4 Institute for Technical Chemistry, Leibniz University Hannover, 30167 Hannover, Germany; \\ stahl@iftc.uni-hannover.de (F.S.); scheper@iftc.uni-hannover.de (T.S.) \\ check for \\ updates \\ * Correspondence: g.garnweitner@tu-braunschweig.de \\ + Contributed equally to the work.
}

Citation: Ag Seleci, D.; Maurer, V.; Barlas, F.B.; Porsiel, J.C.; Temel, B.; Ceylan, E.; Timur, S.; Stahl, F.; Scheper, T;; Garnweitner, G. Transferrin-Decorated Niosomes with Integrated InP/ZnS Quantum Dots and Magnetic Iron Oxide Nanoparticles: Dual Targeting and Imaging of Glioma. Int. J. Mol. Sci. 2021, 22, 4556. https://doi.org/ 10.3390/ijms22094556

Academic Editor:

Giuseppe Lombardi

Received: 24 March 2021

Accepted: 23 April 2021

Published: 27 April 2021

Publisher's Note: MDPI stays neutral with regard to jurisdictional claims in published maps and institutional affiliations.

Copyright: (c) 2021 by the authors. Licensee MDPI, Basel, Switzerland. This article is an open access article distributed under the terms and conditions of the Creative Commons Attribution (CC BY) license (https:// creativecommons.org/licenses/by/ $4.0 /)$

\begin{abstract}
The development of multifunctional nanoscale systems that can mediate efficient tumor targeting, together with high cellular internalization, is crucial for the diagnosis of glioma. The combination of imaging agents into one platform provides dual imaging and allows further surface modification with targeting ligands for specific glioma detection. Herein, transferrin (Tf)-decorated niosomes with integrated magnetic iron oxide nanoparticles (MIONs) and quantum dots (QDs) were formulated (PEGNIO/QDs/MIONs/Tf) for efficient imaging of glioma, supported by magnetic and active targeting. Transmission electron microscopy confirmed the complete co-encapsulation of MIONs and QDs in the niosomes. Flow cytometry analysis demonstrated enhanced cellular uptake of the niosomal formulation by glioma cells. In vitro imaging studies showed that PEG$\mathrm{NIO} / \mathrm{QDs} / \mathrm{MIONs} / \mathrm{Tf}$ produces an obvious negative-contrast enhancement effect on glioma cells by magnetic resonance imaging (MRI) and also improved fluorescence intensity under fluorescence microscopy. This novel platform represents the first niosome-based system which combines magnetic nanoparticles and QDs, and has application potential in dual-targeted imaging of glioma.
\end{abstract}

Keywords: multifunctional niosomes; quantum dots; iron oxide nanoparticles; glioma imaging

\section{Introduction}

Glioma are one of medicine's most challenging problems and lead to a poor prognosis for the patient with a mean survival time of less than 18 months [1]. Only 3-10\% of the patients survive for more than 5 years following diagnosis [2]. Surgical resection, chemotherapy, radiotherapy and novel therapeutic modalities such as immunotherapy, gene therapy, and photodynamic therapy are current treatments for glioma [3]. Surgery is the most effective treatment to increase the survival time of glioma patients. However, the operation bears high risk due to the localization of tumor tissue in the brain, and ineffective resection leads to remaining glioma cells that can proliferate and migrate quickly. An effective tumor resection needs novel imaging techniques for the detection of tumor localization and surgical phases. The commonly used imaging techniques are magnetic resonance imaging (MRI) and computed tomography (CT) $[4,5]$. Although images from CT and MRI can reveal the location of the tumor, it remains difficult to differentiate neoplastic and normal brain tissue because of the poor visual contrast. 
Advances in nanotechnology have triggered a growing interest for the use of nanomaterials in medicine to solve a number of issues associated with therapy and diagnosis. Therapeutic agents have been combined with nanoparticles to minimize toxicity, increase their solubility, prolong the circulation half-life, reduce their immunogenicity, and improve their distribution [6-8]. Multifunctional nanomaterials such as quantum dots (QDs) and polymers have been investigated and have shown great promise in targeted imaging of cancer cells [9-11].

Magnetic iron oxide nanoparticles (MIONs) are extensively used as MRI contrast agents. Dependent on the specific relaxation process, the resulting magnetic resonance (MR) images are classified into longitudinal relaxation time weighted images (T1 contrast) and transverse relaxation time weighted images (T2 contrast). MIONs with a diameter below $4 \mathrm{~nm}$ are preferred as T1 (positive) contrast agents, while nanoparticles with a diameter greater than $4 \mathrm{~nm}$ are used as T2 (negative) contrast agents [12]. MRI-optical dual imaging is a promising approach that can provide more accurate diagnosis than any single imaging modality. In this approach, MRI provides noninvasive in vivo high-resolution anatomical images, while fluorescence imaging can deliver microscopic information in postmortem pathological tissues [13]. Fluorescent dyes such as rhodamine, fluorescein, and conjugated polymers have been used to design a dual-mode probe for biomedical applications [14-16]. Jang et al. presented the synthesis and the use of monodisperse iron oxide nanoparticles coated with fluorescent silica nano-shells for fluorescence and magnetic resonance dual imaging of tumors. The in vitro and in vivo data presented in that study demonstrate the high potential of the designed core-shell nanoparticles as biocompatible dual contrast agents for in vivo biomedical imaging [17]. Although successful cell labeling has been achieved with organic dyes, they are plagued by low quantum yields and photobleaching. Functionalized fluorescent nanoparticles, such as QDs, are promising alternatives for bioimaging [18], showing excellent physical and fluorescent properties, such as size-dependent broad absorption spectra and narrow emission spectra, high quantum yields, resistance to photobleaching, and high photochemical stability [19,20]. However, there is strong concern about the cytotoxicity of QDs, especially for the commonly used cadmium-based materials (in particular, CdSe, and CdS). Numerous studies have demonstrated that these cadmium-based QDs can cause significant DNA damage due to acute toxic effects [21]. Although the cytotoxic effects of cadmium-based QDs can be reduced by controlling the size and the surface ligand chemistry of the particles [22], the use of alternative QDs is preferred for biomedical applications. Indium phosphide (InP) QDs show similar size-dependent optical properties, resistance to photobleaching, and tunable fluorescence to their Cd-based counterparts, but they are less toxic [23]. The degree of toxicity of QDs also depends on their colloidal stability; therefore, the deposition of a $\mathrm{ZnS}$ shell was postulated to provide advantages to avoid, or at least slow down, the decomposition of QDs in intracellular environments [24]. Lin et al. have studied the in vivo long-term toxicity of $\mathrm{InP} / \mathrm{ZnS}$ QDs in BALB/c mice, and observed no acute toxic effects according to hematology, blood biochemistry, and histological analysis [25]. Hence, core/shell-structured InP/ZnS QDs have become popular alternatives to cadmiumcontaining nanomaterials for biomedical applications. However, QDs are mostly produced in organic solvents, making them unsuitable for direct use in biomedical and clinical applications. To overcome this limitation, such QDs can be inserted into lipid bilayers to enhance their hydrophilicity, stability, and biocompatibility [26-28].

Integration of different diagnostic agents into one platform, the so-called "all-in-one" approach, has been postulated as a diagnostic tool for glioma with high potential [29]. Thereby, multifunctional probes can be created by combining MRI agents, fluorescence imaging agents, and photoacoustic imaging agents by using a suitable carrier system [30]. Niosomes are vesicular carriers which provide a bilayer structure that is promising for the design of all-in-one diagnostic systems. Various agents with a wide range of solubilities could be entrapped in the aqueous core or between the membrane bilayers of these structures $[8,31]$. Furthermore, this approach allows us to combine crucial properties 
into one system, such as tumor active targeting, imaging, and specific therapy, which more effectively supplies multimodal methods to combat glioma [32]. Active targeting is promising and can be achieved with the specific binding of targeting ligands conjugated on nanoparticles to receptors overexpressed on the cancer cells [33].

Among others, the transferrin ( $\mathrm{Tf}$ ) receptor is one of the most effective and most commonly used target receptors on cellular surfaces [34]. Tf is an iron-binding blood plasma glycoprotein that controls the level of free iron in biological fluids, while also facilitating the transport of iron to proliferating cells. Tf is internalized into the cells via Tfreceptor-mediated endocytosis. The Tf-receptor is highly expressed in glioma cells because of their rapid proliferation rate as well as large iron demand, whereby tumor xenografts which were generated from cancer cell lines retain the Tf-receptor expression in vivo [35,36]. Therefore, the ability of Tf to internalize via the Tf-receptor, as well as the high level of expression on cancer cells, make it an attractive target for selective delivery of diagnostic and therapeutic agents, especially to brain tumors. Several types of nanoparticles were functionalized with Tf-receptor-binding ligands such as peptides, antibodies, or Tf itself, to deliver therapeutics to the brain $[37,38]$. Furthermore, active targeting can be combined with physical targeting, such as the application of a magnetic field, light, or ultrasound, for efficient glioma targeting via the use of suitable functional nanoparticles.

Here, magnetic iron oxide nanoparticles (MIONs) and InP/ZnS QDs were synthesized and integrated into niosomes. Subsequently, Tf was conjugated to the surface of the niosomes for dual targeting and imaging of glioma. The designed PEGNIO/QDs/MIONs/Tf represents the first niosome-based system combining magnetic nanoparticles and QDs. The physicochemical parameters of the individual components as well as the assembled niosomes, in particular their size, surface charge, and morphology, were investigated in detail. Bioinvestigations, such as cytotoxicity and cellular uptake of the dual imaging systems, were examined with the U87 glioblastoma cell line. The glioma-targeted imaging capability of the nanoparticle-encapsulated niosomes was carefully evaluated under an external magnetic field. The dual imaging of glioma, including MR imaging and fluorescence imaging, was also confirmed in vitro.

\section{Results and Discussion}

\subsection{Characterization of $C A-M I O N$ s and InP/ZnS QDs}

The synthesis of MIONs was performed by co-precipitation of $\mathrm{Fe}^{2+}$ and $\mathrm{Fe}^{3+}$ in alkaline conditions. TGA was performed on dried samples before and after citrate coating (Figure 1A). While the net weight loss for the neat MIONs is about $7.0 \%$, the weight loss for CA-MIONs amounts to $11.7 \%$, which proves the presence of CA on the MIONs and thus successful modification [39]. Moreover, a TEM image of CA-MIONs is shown in Figure 1B, revealing a spherical morphology and relatively uniform size of the obtained particles. XRD was carried out to determine the phase content and crystallinity of the obtained products (Figure S1). The sample presents distinct Bragg reflexes that can be correlated with the reference patterns of magnetite (ICSD: 98-015-8714) and maghemite (ICSD: 98-007-9196). However, it is not possible to distinguish between maghemite and magnetite, as both materials have the same spinel inverse crystal structure; hence, determination of the composition is not possible by XRD analysis [40]. Using the Debye-Scherrer formula, a crystallite size of about $10 \mathrm{~nm}$ was calculated for CA-MIONs which is consistent with the particle size obtained by TEM. Figure S2 shows the FTIR spectra of CA, MIONs and CA-MIONs. The peak at $1710 \mathrm{~cm}^{-1}$ is attributed to the $\mathrm{C}=\mathrm{O}$ vibration in $\mathrm{CA}$. This band shifts to $1600 \mathrm{~cm}^{-1}$ in CA-MIONs due to the binding of CA to the magnetite surface. Carboxylate groups of $\mathrm{CA}$ should complex with the Fe atoms on the magnetite surface and render a partial single bond character to the $\mathrm{C}=\mathrm{O}$ bond, thus weakening it and shifting the stretching vibration frequency to a lower value [41]. The superparamagnetic character of the CA-MIONs is demonstrated by the magnetization curve (Figure S3), revealing a saturation magnetization of $37.1 \mathrm{Am}^{2} / \mathrm{kg}$. In a recent study, we showed that the encapsulation of MIONs into the niosomal structure was achieved with an entrapment efficiency of approx. 
$30 \%$, which results in the formation of superparamagnetic niosomes with reduced saturation magnetization, but also an efficient magnetic targeting capability [42]. Furthermore, the zeta potential and hydrodynamic size of CA-MIONs were measured as $-20.3 \mathrm{mV}$ and $18.7 \mathrm{~nm}$ (Figure S4), respectively.

A)

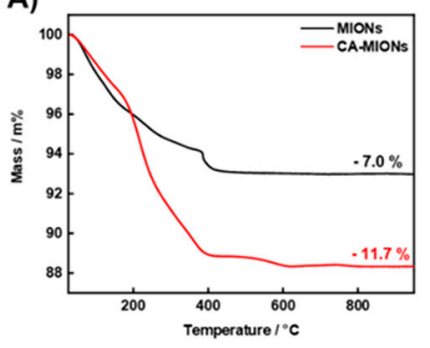

C)

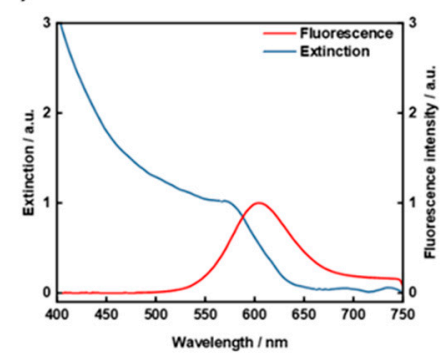

B)

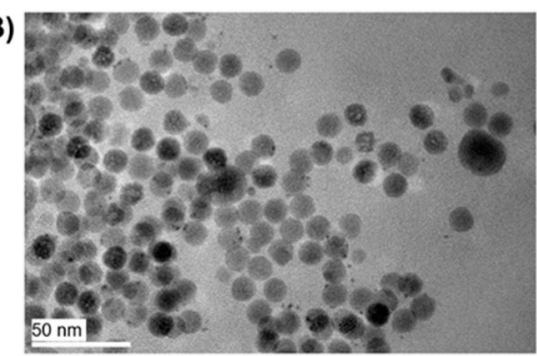

D)

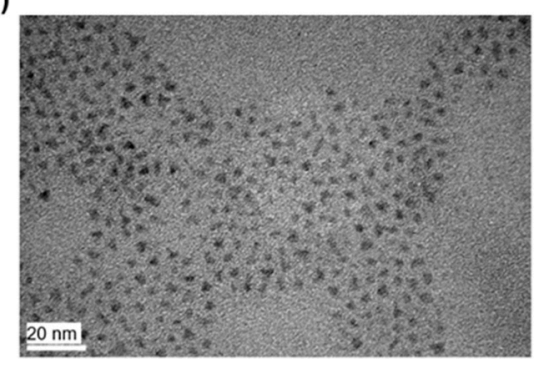

Figure 1. TGA curves of MIONs and CA-MIONs (A), TEM images of CA-MIONs and InP/ZnS QDs $(\mathbf{B}, \mathbf{D})$, and the fluorescence and absorption spectra of InP/ZnS QDs (C).

The optical properties of the obtained InP/ZnS QDs were characterized by UV/Vis and fluorescence spectrophotometry. The fluorescence and extinction spectra of the QDs are shown in Figure 1C. The QDs show orange emission $\left(\lambda_{\mathrm{em}}=600 \mathrm{~nm}\right)$ with an excitation wavelength of $488 \mathrm{~nm}$. The TEM image of InP/ZnS QDs (Figure 1D) demonstrates a relatively monodisperse size distribution with an average size of $\sim 2.5 \mathrm{~nm}$ and mostly trigonal shape.

\subsection{Characterization of Niosomes with Integrated InP/ZnS QDs and CA-MIONs}

The physicochemical properties of vesicular carrier systems, in particular their size, shape, and surface chemistry, play a critical role in determining tissue penetration and cellular delivery [9]. The particle size, electrical potential at the shear plane, and morphology of the prepared samples were characterized by DLS, zeta potential measurements, and TEM images. PEGNIO/QDs/MIONs have a negative zeta potential of $-29.3 \mathrm{mV}$. Coupling of the positively charged Tf protein increased the surface potential of the niosomes, leading to a zeta potential of $-19.8 \mathrm{mV}$ [37]. The average particle size of PEGNIO/QDs/MIONs/Tf was detected to be $178.5 \mathrm{~nm}$ by DLS, which furthermore revealed a monomodal particle size distribution with a PDI of 0.192, demonstrating that the vesicle population is relatively homogeneous in size (Figure S4). Table 1 shows an overview for the hydrodynamic size, PDI and zeta potential of CA-MIONs and the different PEGNIO formulations [6,7]. The morphology of PEGNIO/QDs/MIONs was observed via TEM images at $120 \mathrm{keV}$ as spherical (Figure 2A). To detect the encapsulated QDs and MIONs, the measuring voltage was increased to $200 \mathrm{keV}$, which destroyed the vesicle membrane. The particles inside the vesicles show identical morphology (Figure 2B) to that observed by TEM images of free QDs or free MIONs (Figure 1B,D). Additionally, to confirm the presence of both $\mathrm{InP} / \mathrm{ZnS}$ QDs and MIONs in the niosomes, a photograph of PEGNIO/QDs/MIONs was taken under illumination by UV light and the migration of PEGNIO/QDs/MIONs, when applying a permanent magnet with a magnetic field of $1.3 \mathrm{~T}$, was investigated (Figure S5). Therefore, it is clear that the PEGNIO/QDs/MIONs exhibit fluorescence signals and migrate in the direction of the magnetic field. These results prove that QDs and MIONs were encapsulated 
into the PEGNIO. The stability of PEGNIO/QDs/MIONs/Tf was tested via DLS analysis and no changes were observed in the size and PDI values after one month of storage at $4{ }^{\circ} \mathrm{C}$ in the dark (data not shown).

Table 1. Characteristic properties of CA-MIONs and the different PEGNIO formulations.

\begin{tabular}{cccc}
\hline Sample & Size $(\mathbf{n m})$ & PDI & Zeta Potential $(\mathbf{m V})$ \\
\hline CA-MIONs & 18.7 & 0.221 & -20.3 \\
PEGNIO [6,7] & 150.3 & 0.175 & -33.5 \\
PEGNIO/QDs/MIONs & 156.1 & 0.158 & -29.3 \\
PEGNIO/QDs/MIONs/Tf & 178.5 & 0.192 & -19.8 \\
\hline
\end{tabular}
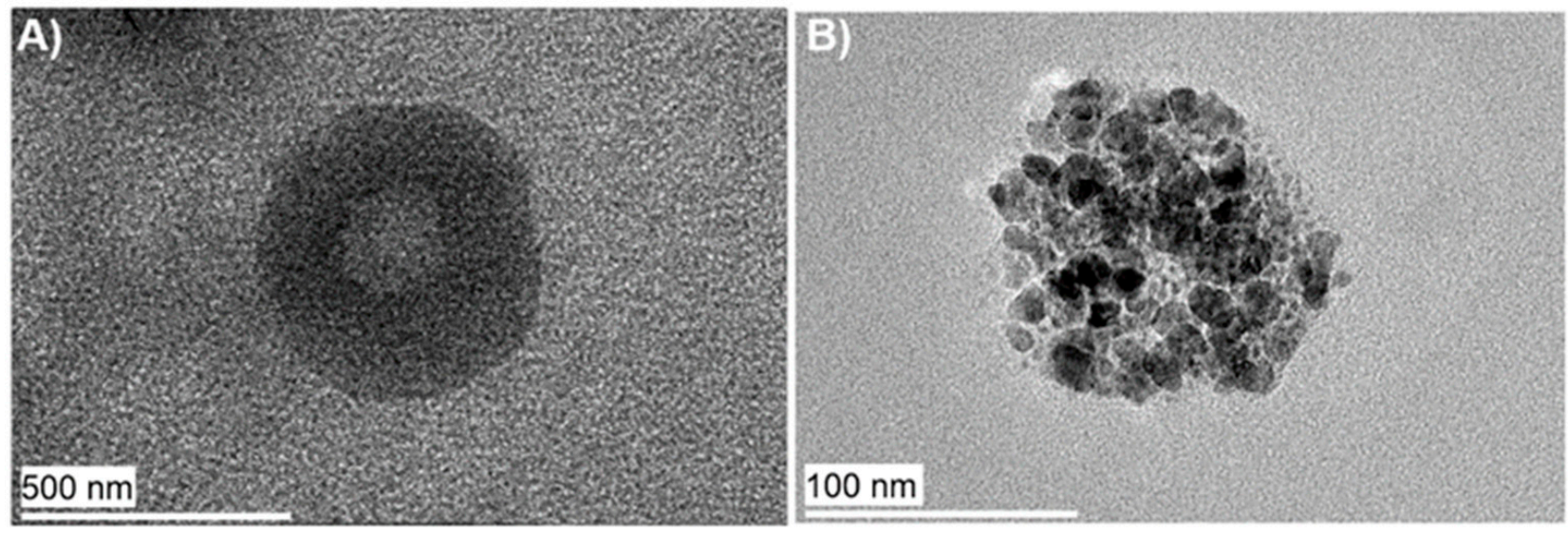

Figure 2. TEM images of PEGNIO/QDs/MIONs obtained at $120 \mathrm{keV}$ (A) and at $200 \mathrm{keV}$ (B).

Additionally, the sample was diluted in cell culture media and was incubated at $37^{\circ} \mathrm{C}$ for $24 \mathrm{~h}$. The size of the sample was measured before and after incubation, and no changes were observed. The photometric characteristics of $\mathrm{InP} / \mathrm{ZnS}$ QD after encapsulation were examined by fluorescence spectrophotometry. As shown in Figure S6, the fluorescence emission spectrum of PEGNIO/QDs/MIONs was similar to that of InP/ZnS QDs. Encapsulation into niosomes reduced the fluorescence intensity of the QDs to some extent, possibly due minor absorption effects of the niosome shell or the MIONs, but it did not result in a shift of the emission wavelength.

\subsection{Cytotoxicity}

A CTB assay was used to determine the cytotoxicity of PEGNIO/QDs/MIONs and $\mathrm{PEGNIO/QDs/MIONs/Tf} \mathrm{on} \mathrm{U87} \mathrm{cells} \mathrm{in} \mathrm{the} \mathrm{presence} \mathrm{or} \mathrm{absence} \mathrm{of} \mathrm{an} \mathrm{external} \mathrm{magnetic}$ field. The cells were incubated with different concentrations of PEGNIO/QDs/MIONs and PEGNIO/QDs/MIONs/Tf for $24 \mathrm{~h}$. The ratio of all niosome components was fixed, the given Fe concentration is a measure for the overall concentration of the niosome system. The obtained values of cell viability are presented in Figure 3. The cytotoxicity of PEGNIO/QDs/MIONs and PEGNIO/QDs/MIONs/Tf with magnet treatment (MT) was stronger than without MT. The calculated half inhibition concentration $\left(\mathrm{IC}_{50}\right)$ of PEGNIO/QDs/MIONs was $0.50 \mathrm{mM}$ and $0.31 \mathrm{mM}(p<0.05)$ for the systems without MT and with MT, respectively. The conjugation of the targeting ligand to the PEGNIO/QDs/MIONs increased their toxicity to U87 cells. $\mathrm{IC}_{50}$ values were calculated to be $0.39 \mathrm{mM}$ (without MT) and $0.23 \mathrm{mM}$ (with MT) for PEGNIO/QDs/MIONs/Tf $(p<0.05)$. This may be due to the dual targeting effect of PEGNIO/QDs/MIONs/Tf, which were mainly internalized by receptor-mediated endocytosis. The presence of external magnetic fields supports the attachment of niosomes alongside the cell layer, providing a higher availability of the nanoparticles at the target sites. 
A)

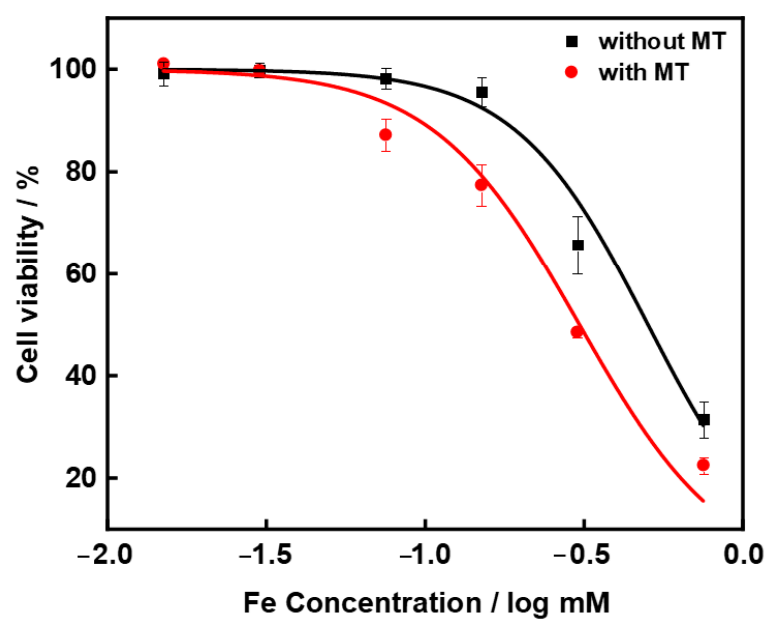

B)

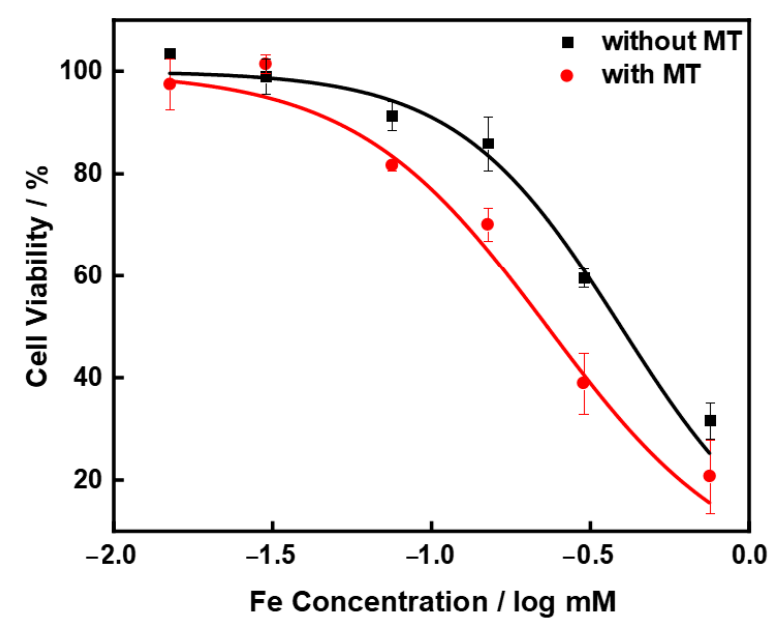

Figure 3. U87 cell viability of PEGNIO/QDs/MIONs (A) and PEGNIO/QDs/MIONs/Tf (B) at different concentrations with (with MT) or without (without MT) a preceding magnetic treatment. For the calculated half inhibition concentrations $\left(\mathrm{IC}_{50}\right)$, we evaluated $p<0.05$ by using the Student's $t$-test, which is thus considered as significant.

\subsection{Cellular Internalization and Uptake}

Tf has previously been shown to be a promising targeting ligand with high specificity and affinity for glioma [37,43-46]. The cellular internalization of PEGNIO/QDs/MIONs and PEGNIO/QDs/MIONs/Tf was determined via fluorescence microscopy studies. The niosome dispersions were diluted with medium and then added to the cells. To evaluate the effect of an external magnetic field on cellular uptake, a $1.3 \mathrm{~T}$ permanent magnet was placed under the cell-growth plate for $15 \mathrm{~min}$. Afterward, the cells were incubated for $4 \mathrm{~h}$ at $37^{\circ} \mathrm{C}$ without an external magnetic field and washed once in PBS. Fluorescence microscopy revealed that QDs were localized in both the cytosol and nuclear envelope of glioma cells (Figure 4), evidencing the successful delivery of QDs via the niosomal system. In a similar vein to our results, biocompatible cationic $\mathrm{InP} / \mathrm{ZnS}$ QDs were applied to breast cells in an earlier study by Devatha et al. and confocal microscopy images showed the fluorescence of InP/ZnS QDs inside the cytosol of breast cancer cells [47].

Non-specific cellular internalization of PEGNIO/QDs/MIONs was observed in glioma cells (Figure 4A), however, cellular internalization showed a 2.4-fold enhancement in relative fluorescent units (RFU) due to the magnetic treatment (Figure 4B). Modifying the niosome surface with $\mathrm{Tf}$ allows for a 2.7 -fold higher cellular uptake through Tfreceptor-mediated endocytosis (Figure 4C) compared to plain cellular internalization of PEGNIO/QDs/MIONs. In particular, the application of PEGNIO/QDs/MIONs/Tf together with an external magnetic field resulted in a 3.1-fold enhancement in RFU due to the cumulative effect of magnetic guidance and the enhanced Tf-receptor-based attachment on the cell surface (Figure 4D). These results clearly demonstrate the efficient dual targeting modality of the niosomal system.

Furthermore, flow cytometry was used to additionally evaluate the receptor-mediated cell targeting efficacy of niosomes on U87 cells. The cells were treated with PEGNIO/QDs/ MIONs and PEGNIO/QDs/MIONs/Tf for $2 \mathrm{~h}$. Untreated control cells and treated cells were analyzed using a BD Accuri C6 flow cytometer. Figure 5 indicates that PEG$\mathrm{NIO} / \mathrm{QDs} / \mathrm{MIONs} / \mathrm{Tf}$ was taken up by U87 cells specifically. Tf is able to selectively bind to tumor cells via the Tf receptor, which is overexpressed in glioma cells [48]. The higher expression of Tf receptors on U87 cells enables a much greater proportion of targeted niosomes to enter the cells via receptor-mediated endocytosis, in comparison to non-targeted niosomes. We verified this Tf-receptor-mediated endocytosis of Tf-functionalized PEGNIO formulations by Tf-receptor-expressing U87 glioma cells via performing flow-cytometric 
cellular uptake measurements of fluorescence-labeled PEGNIO/Tf in Tf-receptor negative cells (A549, which expresses hardly any Tf-receptors [49]) (Figure S7). Because, in this case, the internalization of PEGNIO and PEGNIO/Tf was shown to be almost uniform and therefore independent of Tf-functionalization, the presented enhanced internalization of Tf-labeled PEGNIO/QDs/MIONs by U87 cells can be attributed to a Tf-based endocytosis.
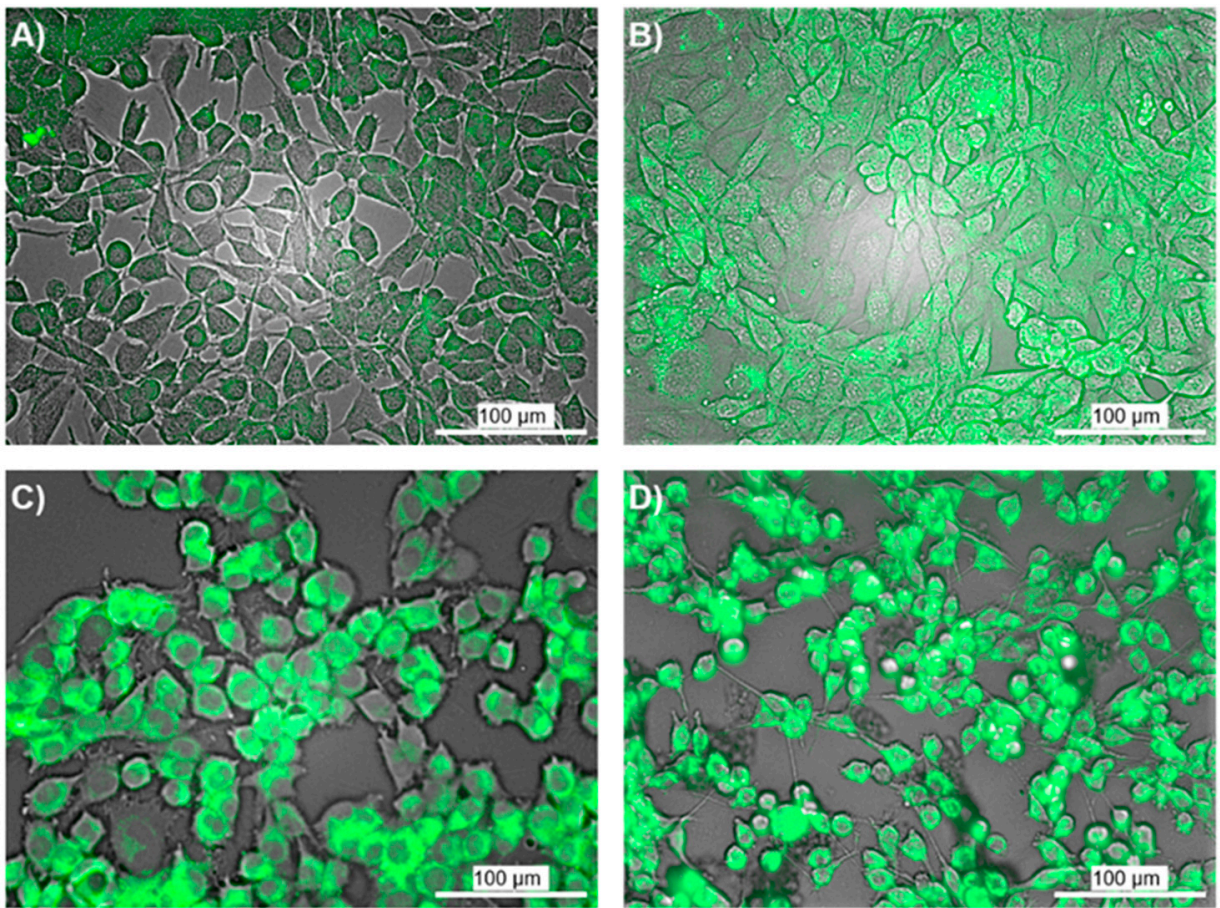

Figure 4. Fluorescence microscopy images of U87 cells after incubating with PEGNIO/QDs/MIONs ((A): without MT; (B): with MT) and PEGNIO/QDs/MIONs/Tf ((C): without MT; (D): with MT). The quantification procedure was evaluated with $p<0.05$, and is therefore significant.

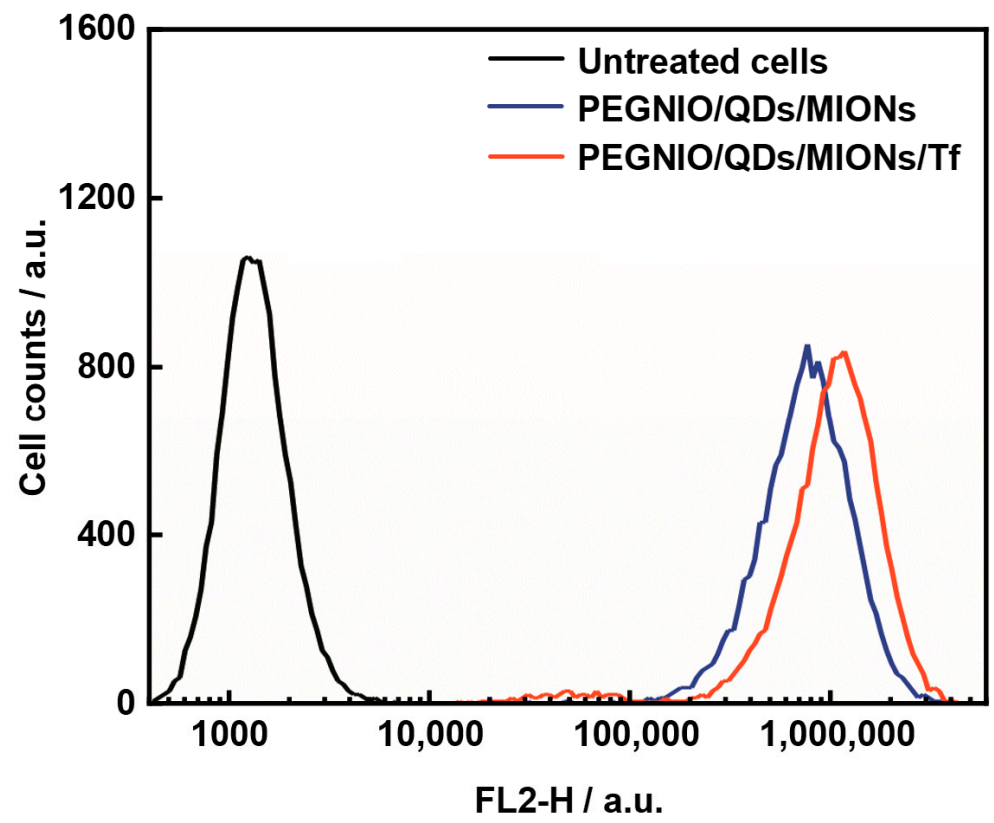

Figure 5. Flow cytometric measurement of the uptake of PEGNIO/QDs/MIONs and PEG$\mathrm{NIO} / \mathrm{QDs} / \mathrm{MIONs} / \mathrm{Tf}$ by U87 cells. 


\subsection{MR Imaging}

MIONs are among the most used diagnostic tools in cancer, with T2-weighted MRI as a common application [50,51]. In addition to the fluorescence imaging technique, MRI was applied to the U87 cells after administration of the newly developed diagnostic nanoparticle system. To compare the effectiveness of PEGNIO/QDs/MIONs/Tf, the control group (cells without treatment) was also investigated via MRI (Figure 6A). Figure 6B presents an MR image after the incorporation of PEGNIO/QDs/MIONs/Tf into the glioma cells with an obvious negative-contrast enhancement. The contrast density difference between control and sample is shown in Figure 6C. These results prove that PEGNIO/QDs/MIONs/Tf has great potential to be a contrast and fluorescent dual imaging agent for glioma diagnosis.
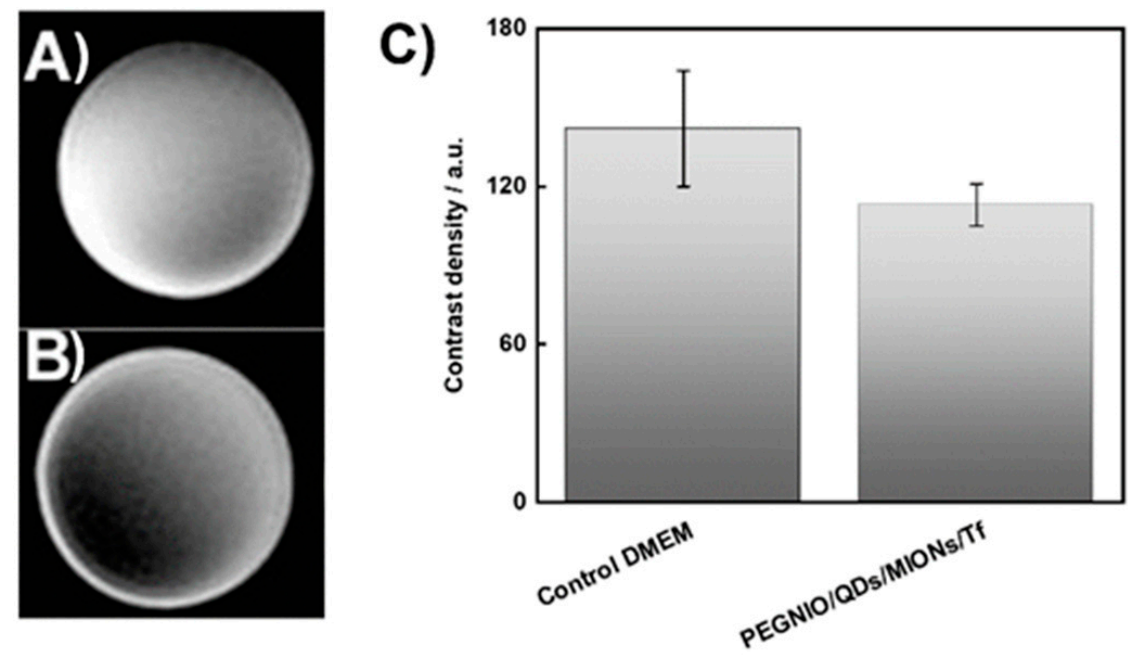

Figure 6. MRI of U87 cells after $2 \mathrm{~h}$ incubation with control DMEM (A) and PEGNIO/QDs/MIONs/Tf (B). The histograms show the density of the MR images $(\mathbf{C})$. Error bar means \pm S.D. $(n=4)$ with $p<0.05$.

\section{Materials and Methods}

\subsection{Materials}

1,2-distearoyl-sn-glycero-3-phosphoethanolamine- $N$-[maleimide(polyethyleneglycol)2000] (DSPE-PEG(2000) maleimide) was provided by Avanti (Alabaster, AL, USA). Sorbitan monostearate (Span60), cholesterol, iron(II) chloride tetrahydrate $\left(\mathrm{FeCl}_{2} \cdot 4 \mathrm{H}_{2} \mathrm{O}\right)$, iron(III) chloride hexahydrate $\left(\mathrm{FeCl}_{3} \cdot 6 \mathrm{H}_{2} \mathrm{O}\right)$, citric acid (CA), indium(III) chloride $\left(\mathrm{InCl}_{3}\right)$, zinc(II) chloride $\mathrm{ZnCl}_{2}$, tris(dimethylamino)phosphine (TDMAP), dodecanethiol (DDT), 4-(2hydroxyethyl)-1-piperazineethanesulfonic acid (HEPES), ethylenediaminetetraacetic acid (EDTA), zinc stearate, oleylamine (OLA), Dulbecco's Modified Eagle Medium (DMEM), transferrin (Tf), and 2-iminothiolane hydrochloride (Traut's reagent) were purchased from Sigma-Aldrich (Munich, Germany).

\subsection{Synthesis and Characterization of CA-MIONs}

Citrate-coated magnetic iron oxide nanoparticles (CA-MIONs) were synthesized via a co-precipitation method [41,52]. $0.75 \mathrm{~g}$ of $\mathrm{FeCl}_{3} \cdot 6 \mathrm{H}_{2} \mathrm{O}$ and $0.375 \mathrm{~g}$ of $\mathrm{FeCl}_{2} \cdot 4 \mathrm{H}_{2} \mathrm{O}$ were dissolved in $50 \mathrm{~mL}$ of distilled water and mixed at $80^{\circ} \mathrm{C}$ under nitrogen atmosphere in a $100 \mathrm{~mL}$ three-neck flask equipped with a reflux condenser. After $10 \mathrm{~min}, 10 \mathrm{~mL}$ of $\mathrm{NH}_{4} \mathrm{OH}$ (28-32\% aq.) was added dropwise to the reaction mixture. $1 \mathrm{~h}$ after the beginning of the reaction, a previously prepared CA solution ( $1.0 \mathrm{~g}$ in $2 \mathrm{~mL}$ of distilled water) was injected into the reaction mixture. The reaction temperature was increased to $95^{\circ} \mathrm{C}$ and the system stirred for one further hour. Subsequently, the resulting nanoparticle dispersion was left to cool to room temperature and washed twice with deionized water via decantation under 
magnetic fixation of the nanoparticles. Additionally, the dispersion was purified for $24 \mathrm{~h}$ using a 12-14 $\mathrm{kDa}$ dialysis bag to remove excess unbound CA.

\subsection{Synthesis and Characterization of InP/ZnS QDs}

The synthesis of stabilized zinc sulfide-coated indium phosphide ( $\mathrm{InP} / \mathrm{ZnS})$ core-shell quantum dots was adapted from Ellis et al. with minor adjustments (see SI Section for details) [53].

\subsection{Preparation of Niosomes Loaded with InP/ZnS QDs and CA-MIONs}

The niosomal nanoparticles (PEGNIO/QDs/MIONs) were prepared by the thinfilm hydration method [54]. Span 60, cholesterol, and DSPE-PEG(2000) maleimide were dissolved in chloroform with the molar ratio of 4.95:4.95:0.1. Then, $100 \mu \mathrm{L}$ of the InP/ZnS quantum dots dispersed in chloroform were added to the niosomal precursor solution in a round-bottom flask. The solvent was evaporated with constant rotation under reduced pressure to form a thin lipid film. Afterwards, the thin film was hydrated with $1.0 \mathrm{~mL}$ of CA-MIONs aqueous solution at $60^{\circ} \mathrm{C}$ for $60 \mathrm{~min}$. A schematic representation of the niosome synthesis and nanoparticle encapsulation processes is shown in Scheme 1. The prepared multilamellar vesicles were processed to form small unilamellar vesicles by extrusion (extruder provided by Avanti Polar Lipids, USA) through $0.4 \mu \mathrm{m}$ and $0.1 \mu \mathrm{m}$ pore size polycarbonate filters (Cytiva Life Sciences, Dassel, Germany). Subsequently, the niosome dispersion was centrifuged at 11,000 rpm for $15 \mathrm{~min}$ and the sediment redispersed in water to remove the excess non-incorporated quantum dots and CA-MIONs.

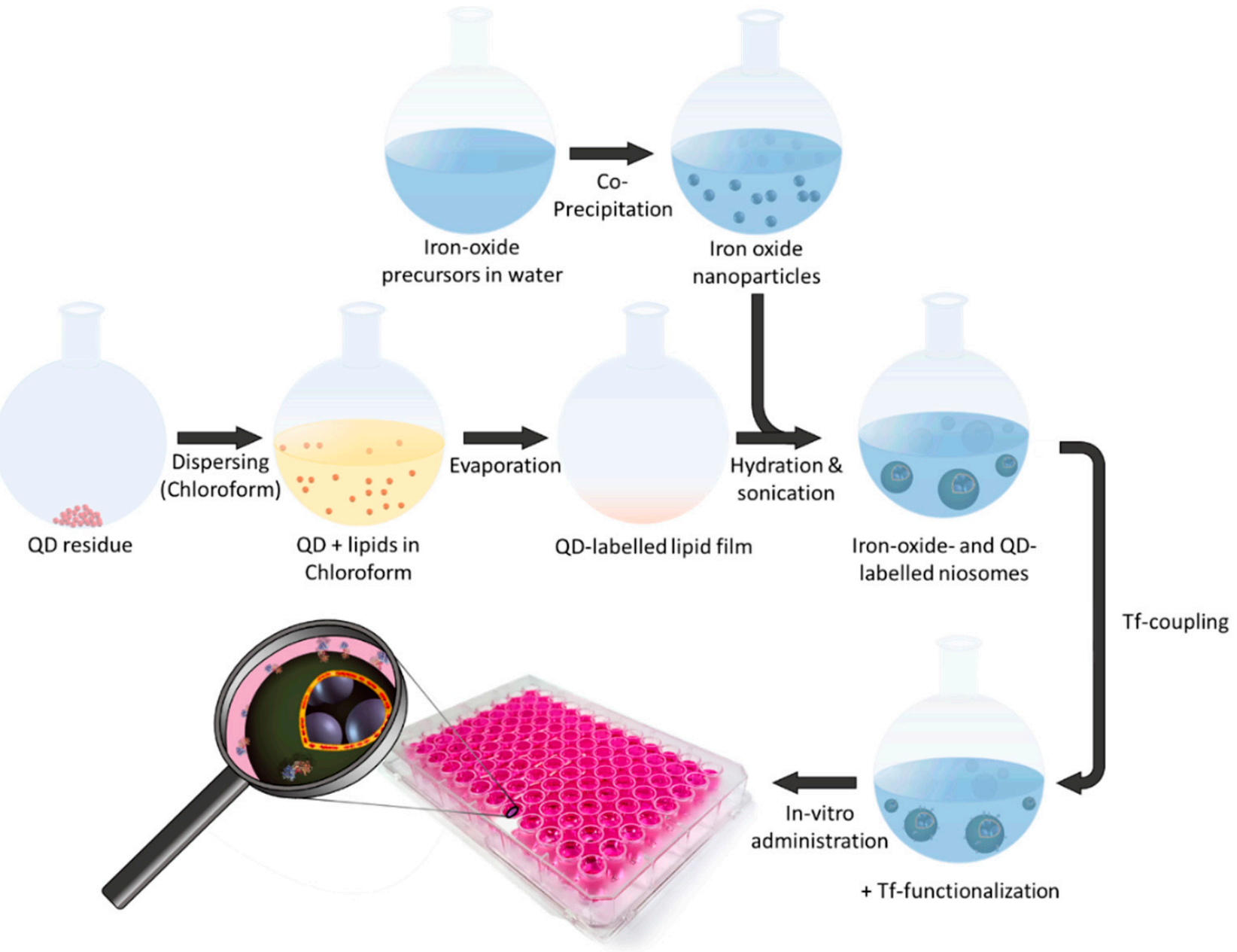

Scheme 1. Schematic representation of the PEGNIO/QDs/MIONs/Tf formation and application. 


\subsection{Preparation of Transferrin-Conjugated Niosomes}

Tf-targeted niosomal nanoparticles (PEGNIO/QDs/MIONs/Tf) were prepared via the attachment of Tf to the niosome surface. This was achieved using $5 \mathrm{nmol}$ Tf and $25 \mathrm{nmol}$ 2-iminothiolane (Traut's reagent) in $500 \mu \mathrm{L}$ HEPES EDTA buffer, at pH 8.5 (30 mM HEPES and $0.1 \mathrm{mM}$ EDTA). The mixture was incubated for $2 \mathrm{~h}$ at room temperature while shaking to complete the thiolation of Tf. Thiolated Tf was then washed with HEPES pH 6.5 in a concentration column ( $30 \mathrm{kDa}$, Amicon ${ }^{\circledR}$ by Millipore) and concentrated to a final volume of $200 \mu \mathrm{L}$. The loaded Tf was immediately added to the niosomes and incubated for $24 \mathrm{~h}$ at $4{ }^{\circ} \mathrm{C}$ resulting in the formation of a thioether linkage [55]. The thiol group of $\mathrm{Tf}$ was coupled with the maleimide group of the PEG chains on the niosomes.

\subsection{Characterization of Niosomes}

The size and zeta potential of the prepared nanoparticles were measured by DLS analysis using the Zetasizer Nano ZS and the Zetasizer Nano software (v7.12) from Malvern Panalytical (Kassel, Germany). The polydispersity index (PDI) was used as a measure of the width of the size distribution. The measurements were performed at $23{ }^{\circ} \mathrm{C}$ with a $173^{\circ}$ backscattering setup. A previous dilution of the samples by a factor of $10^{4}-10^{5}$ minimized occurring fluorescence. To obtain the hydrodynamic diameter, the modal value of the respective intensity distribution was taken. The zeta potentials were attained using a capillary zeta cuvette (DTS1070C, Malvern Panalytical Ltd.).

The morphology of the niosomes after integration of the nanoparticles was monitored via transmission electron microscopy (TEM). Briefly, one drop of the niosome dispersion was applied onto a carbon film on a $3.05 \mathrm{~mm}$ woven copper net with 300 mesh (Plano $\mathrm{GmbH}$, Wetzlar, Germany). The remaining liquid was removed by blotting onto filter paper. Then, staining with $2 \%$ aqueous phosphotungstic acid was performed without removing the excess, but while allowing evaporation. The samples were observed using a Tecnai G ${ }^{2}$ F20 TMP (turbo-molecular pump) from Fei (Hillsboro, OR, USA), operating at an accelerating voltage of $120 \mathrm{keV}$ and $200 \mathrm{keV}$ in a bright-field image mode.

For the powder X-ray diffraction (XRD) analysis, an Empyrean series 2 from Malvern Panalytical (Kassel, Germany) with $\mathrm{Cu}-\mathrm{K}_{\alpha}$ radiation (wavelength $\lambda$ of $0.154 \mathrm{~nm}$ ) was used. The MIONs were dried in an oven, put onto a Si sample holder and measured in a range of $20^{\circ}-90^{\circ} 2 \theta$ with a step size of $0.05^{\circ}$. The obtained diffractogram was compared with reference patterns from the Inorganic Crystal Structure Database (ICSD).

The surface chemistry of the MIONs was analyzed by attenuated total reflectance Fourier-transform infrared spectroscopy (ATR-FTIR) using a Vertex 70 device from Bruker (Billerica, MA, USA), after drying the sample in an oven overnight.

Thermogravimetric analysis (TGA) was performed using a TGA/DSC 1 STARe system and a gas controller 4C200 STARe system from Mettler Toledo (Columbus, OH, USA). $15 \mathrm{mg}$ of the dried sample was placed in a ceramic crucible and measured at a heating rate of $10{ }^{\circ} \mathrm{C} / \mathrm{min}$ under, an oxygen atmosphere.

The magnetic behavior and saturation magnetization of MIONs was examined via a superconducting quantum interference device (SQUID) using the MPMS-5S instrument from Quantum Design. The samples were dried analogously to the FTIR preparation.

The optical properties of the QDs and PEGNIO/QDs/MIONs were analyzed by $\mathrm{UV} /$ Vis spectrometry, measuring in a $1.0 \mathrm{~cm}$ quartz glass cuvette using a UV-3100PC UV-Vis spectrophotometer from VWR (Radnor, PA, USA).

The iron concentration in the niosomal samples was determined via a spectrophotometric technique. Standard solutions of $\mathrm{Fe}^{3+}$ containing 0.1-10 mM Fe were prepared. $10 \mu \mathrm{L}$ of samples or standards were mixed with $500 \mu \mathrm{L}$ of hydrochloric acid and hydrogen peroxide solution $\left(10 \mathrm{~mL}\right.$ of $6 \mathrm{M} \mathrm{HCl}$ and $10 \mu \mathrm{L}$ of $30 \% \mathrm{H}_{2} \mathrm{O}_{2}$ ). Samples were incubated with the solution for $30 \mathrm{~min}$ at room temperature and the optical density of the solution was measured at $410 \mathrm{~nm}$ using the UV-3100PC UV-Vis spectrophotometer. The iron concentrations of the samples were calculated from a calibration curve obtained from the standards. 
The colloidal stability of the niosomal formulations was tested via DLS analysis. All samples were stored at $4{ }^{\circ} \mathrm{C}$ in the dark. The particle size and PDI values were measured repeatedly over the period of one month. Moreover, the particle size of PEG$\mathrm{NIO} / \mathrm{QDs} / \mathrm{MIONs} / \mathrm{Tf}$ was measured in cell culture media and PBS after incubation at $37^{\circ} \mathrm{C}$ for $24 \mathrm{~h}$.

\subsection{Cellular Uptake and Internalization}

U87 cell lines were provided from the German Collection of Microorganisms and Cell Cultures (DSMZ). U87 cells were grown in DMEM containing 10\% fetal calf serum (FCS) (Biochrom GmbH, Berlin, Germany) and 1.0\% penicillin/streptomycin (P/S, SigmaAldrich). Cells were cultivated and incubated with samples at $37{ }^{\circ} \mathrm{C}$ in a humidified environment with $5.0 \% \mathrm{CO}_{2}$.

The uptake of the nanoparticle-loaded niosomal formulations by U87 cells was analyzed by flow cytometry. The cells $\left(5 \cdot 10^{5}\right)$ were treated with niosome samples for $2 \mathrm{~h}$, washed twice with PBS, and then analyzed in a BD Accuri C6 cytometer (BD Biosciences, San Jose, CA, USA) using the FL-2 channel with the excitation wavelength at $488 \mathrm{~nm}$. As a control, untreated U87 cells were used. At least 20,000 gated events were observed in total, and living cells were gated in a dot plot of forward versus side scatter signals. The dot plot and histogram data were analyzed by Flowing Software 2.

Cellular internalization of the samples was determined via fluorescence microscopy using a Cytation 5 imaging reader (BioTek Instruments Inc., Winooski, VT, USA). U87 cells were cultivated for 2 days on 96 well plates in $200 \mu \mathrm{L}$ of the medium. The samples (PEGNIO/QDs/MIONs and PEGNIO/QDs/MIONs/Tf) were diluted with cell culture medium and then added to the cells. To evaluate the effect of an external magnetic field on cellular uptake, a neodymium magnet with a magnetic field of $1.3 \mathrm{~T}$ was placed under the cell-growing plate for $15 \mathrm{~min}$. Afterwards, the cells were incubated for $4 \mathrm{~h}$ at $37^{\circ} \mathrm{C}$ without an external magnetic field and washed once in PBS. The fluorescence images were evaluated by calculating the enhancement factor using the ImageJ software according to Balasubramanian et al. [56].

\subsection{Cytotoxicity}

The metabolic activity of viable cells, in terms of their reduction capacity of resazurin, was measured via CTB assay (CellTiter-Blue ${ }^{\circledR}$ cell viability assay, Promega Corp., Madison, USA). The cytotoxic effects of niosomal formulations were tested on U87 cells. Cells $\left(8 \cdot 10^{3}\right)$ were seeded out in 96-well tissue plates (Sarstedt, Nümbrecht, Germany) in a volume of $200 \mu \mathrm{L}$ and cultivated for three days. After this cultivation time, the cells were washed once with PBS, treated with PEGNIO/QDs/MIONs and were exposed to an external magnetic field for 15 min by placing a neodymium magnet with a magnetic field of $1.3 \mathrm{~T}$ under the well plate. After further incubation for $24 \mathrm{~h}$, the cells were washed twice with PBS. Then, $100 \mu \mathrm{L}$ of CTB reagent (diluted 1: 6 with supplement-free DMEM medium) was added to each well and incubated for $1 \mathrm{~h}\left(37^{\circ} \mathrm{C}, 5 \% \mathrm{CO}_{2}\right)$. The resulting fluorescence intensities (544Ex/590Em) were recorded with a fluorescence spectrometer (Fluoroskan Ascent, Thermo Fischer Scientific Inc., Waltham, MA, USA). Furthermore, $\mathrm{IC}_{50}$ values (the concentration required for $50 \%$ inhibition of cell viability) were calculated for U87 cells using the growth sigmoidal/dose-response function of Origin software. The equivalent concentration of Fe was used in the niosomal formulations.

\section{9. $M R$ Imaging}

For MRI, 8,000 U87 cells were seeded and incubated for two days in a 6 well-plate (Sarstedt, Nümbrecht, Germany). After that, a PEGNIO/QDs/MIONs/Tf dispersion sample was applied to the cells for $2 \mathrm{~h}$. Then, the medium was removed from the wells and the cells were washed with PBS twice. Next, pure medium was added into the wells, and MR imaging was carried out using the T2-weighted state of the SIGNA Explorer (1.5 T, $60 \mathrm{~cm}$ ) by GE Healthcare (Chicago, IL, USA). Then, the amount of contrast was measured 
with the Image J software by generating an MRI histogram. The negative control was prepared with U87 cells using only the medium under the same conditions.

\subsection{Statistical Analysis}

The statistical evaluation of the results (cytotoxicity, fluorescence microscopy, and MRI studies) was investigated by performing the Student's $t$-test. The difference between two groups was considered significant when the $p$-value was less than 0.05 .

\section{Conclusions}

In the described approach, $\mathrm{InP} / \mathrm{ZnS}$ quantum dots and CA-MIONs were integrated into shell and core, respectively, of a niosomal structure. The resulting niosomes exhibited both fluorescent and magnetic properties with low cytotoxicities. The incorporation of CA-MIONs allowed MR imaging and, simultaneously, magnetic targeting of a whole imaging system. In a further step, Tf was covalently bound to the surface of niosomes to target glioma cells overexpressing $\mathrm{Tf}$ receptors. For the evaluation of the specific binding efficiency and cellular localization, niosomal formulations were applied to glioma cells. Our results show that PEGNIO/QDs/MIONs/Tf bind to Tf-positive glioma cells more effectively than PEGNIO/QDs/MIONs. In vitro imaging studies revealed that PEG$\mathrm{NIO} / \mathrm{QDs} / \mathrm{MIONs} / \mathrm{Tf}$ produce an obvious negative-contrast enhancement effect on glioma cells by magnetic resonance imaging; moreover, they present improved fluorescence intensity under fluorescence microscopy, especially with external magnet treatment. The results thus indicate the high potential of multifunctional niosomes for cell-specific dual targeting and dual imaging of glioma. To validate the in vitro results as well as investigate potential side effects, in vivo experiments with a special focus on the safe and selective delivery of the diagnostic nanocarriers will be necessary. In essence, the development of the targeted niosomal formulation reported here may provide a platform for a new generation of targeting and labeling systems.

Supplementary Materials: The following are available online at https:/ /www.mdpi.com/article/10 .3390/ijms22094556/s1, Figure S1. XRD pattern of the CA-MION nanoparticle powder; Figure S2. FTIR spectra of neat CA, MIONs and CA-MIONs; Figure S3. Magnetization curve of CA-MIONs; Figure S4. Dynamic light scattering measurements of CA-MIONs and PEGNIO/QDs/MIONs; Figure S5. Image of PEGNIO/QDs/MIONs under UV light and migration of PEGNIO/QDs/MIONs after external magnetic field treatment; Figure S6. Fluorescence spectra of QDs and PEGNIO/QDs/ MIONs; Figure S7. Flow-cytometric measurement of rhodamine 6G-labeled PEGNIO and PEG$\mathrm{NIO} /$ Tf uptake by Tf-receptor-negative A549 cells.

Author Contributions: D.A.S. and V.M. designed and performed the experiments, analyzed data and wrote the paper; J.C.P. synthesized QDs; B.T. performed particle analysis; F.B.B. and E.C. contributed to cell culture tests; G.G., F.S., S.T. and T.S. contributed writing the paper. All authors have read and agreed to the published version of the manuscript.

Funding: This research was partially funded by Niedersächsisches Ministerium für Wissenschaft und Kultur through the "Quantum- and Nano-Metrology (QUANOMET)" initiative (ZN3245) within the project NP-1. Moreover, we acknowledge support from the German Research Foundation and the Open Access Publication Funds of Technische Universität Braunschweig.

Institutional Review Board Statement: Not applicable.

Informed Consent Statement: Not applicable.

Data Availability Statement: Data are available upon request.

Acknowledgments: The authors thank the Laboratory of Nano and Quantum Engineering (LNQE) of the Leibniz University of Hannover for the TEM instrument.

Conflicts of Interest: The authors declare no conflict of interest. 


\section{References}

1. Colombo, M.C.; Giverso, C.; Faggiano, E.; Boffano, C.; Acerbi, F.; Ciarletta, P. Towards the Personalized Treatment of Glio-blastoma. PLoS ONE 2015, 10, e0132887.

2. Tamimi, A.F.; Juweid, M. Glioblastoma. In Epidemiology and Outcome of Glioblastoma; Exon Publications: Brisbane, Australia, 2017.

3. Paolillo, M.; Boselli, C.; Schinelli, S. Glioblastoma under Siege: An Overview of Current Therapeutic Strategies. Brain Sci. 2018, 8, 15. [CrossRef] [PubMed]

4. Liu, H.; Zhang, J.; Chen, X.; Du, X.-S.; Zhang, J.-L.; Liu, G.; Zhang, W.-G. Application of iron oxide nanoparticles in glioma imaging and therapy: From bench to bedside. Nanoscale 2016, 8, 7808-7826. [CrossRef] [PubMed]

5. Li, D.; Zhang, J.; Chi, C.; Xiao, X.; Wang, J.; Lang, L.; Ali, I.; Niu, G.; Zhang, L.; Tian, J.; et al. First-in-human study of PET and optical dual-modality image-guided surgery in glioblastoma using 68Ga-IRDye800CW-BBN. Theranostics 2018, 8, 2508-2520. [CrossRef]

6. Seleci, D.A.; Seleci, M.; Stahl, F.; Scheper, T. Tumor homing and penetrating peptide-conjugated niosomes as multi-drug carriers for tumor-targeted drug delivery. RSC Adv. 2017, 7, 33378-33384. [CrossRef]

7. Seleci, D.A.; Seleci, M.; Jochums, A.; Walter, J.-G.; Stahl, F.; Scheper, T. Aptamer mediated niosomal drug delivery. RSC Adv. 2016, 6, 87910-87918. [CrossRef]

8. Seleci, D.A.; Maurer, V.; Stahl, F.; Scheper, T.; Garnweitner, G. Rapid Microfluidic Preparation of Niosomes for Targeted Drug Delivery. Int. J. Mol. Sci. 2019, 20, 4696. [CrossRef]

9. Seleci, M.; Seleci, D.A.; Joncyzk, R.; Stahl, F.; Blume, C.; Scheper, T. Smart multifunctional nanoparticles in nanomedicine. BioNanoMaterials 2016, 17, 33-41. [CrossRef]

10. Ag, D.; Bongartz, R.; Dogan, L.E.; Seleci, M.; Walter, J.-G.; Demirkol, D.O.; Stahl, F.; Ozcelik, S.; Timur, S.; Scheper, T. Bio-functional quantum dots as fluorescence probe for cell-specific targeting. Colloids Surf. B 2014, 114, 96-103. [CrossRef]

11. Ag, D.; Seleci, M.; Bongartz, R.; Can, M.; Yurteri, S.; Cianga, I.; Stahl, F.; Timur, S.; Scheper, T.; Yagci, Y. From invisible struc-tures of SWCNTs toward fluorescent and targeting architectures for cell imaging. Biomacromolecules 2013, 14, 3532-3541. [CrossRef]

12. Javed, Y.; Akhtar, K.; Anwar, H.; Jamil, Y. MRI based on iron oxide nanoparticles contrast agents: Effect of oxidation state and architecture. J. Nanoparticle Res. 2017, 19, 366. [CrossRef]

13. Karki, K.; Ewing, J.R.; Ali, M.M. Targeting Glioma with a Dual Mode Optical and Paramagnetic Nanoprobe across the Blood-brain Tumor Barrier. J. Nanomed. Nanotechnol. 2016, 7, 1-5. [CrossRef]

14. Rivas, C.; Stasiuk, G.J.; Gallo, J.; Minuzzi, F.; Rutter, G.A.; Long, N.J. Lanthanide(III) complexes of rhodamine-DO3A con-jugates as agents for dual-modal imaging. Inorg. Chem. 2013, 52, 14284-14293. [CrossRef]

15. Mishra, A.; Pfeuffer, J.; Mishra, R.; Engelmann, J.; Mishra, A.K.; Ugurbil, K.; Logothetis, N.K. A New Class of Gd-Based DO3AEthylamine-Derived Targeted Contrast Agents for MR and Optical Imaging. Bioconjugate Chem. 2006, 17, 773-780. [CrossRef] [PubMed]

16. Sun, M.; Sun, B.; Liu, Y.; Shen, Q.-D.; Jiang, S. Dual-Color Fluorescence Imaging of Magnetic Nanoparticles in Live Cancer Cells Using Conjugated Polymer Probes. Sci. Rep. 2016, 6, 22368. [CrossRef]

17. Jang, H.; Lee, C.; Nam, G.-E.; Quan, B.; Choi, H.J.; Yoo, J.S.; Piao, Y. In vivo magnetic resonance and fluorescence dual imaging of tumor sites by using dye-doped silica-coated iron oxide nanoparticles. J. Nanoparticle Res. 2016, 18, 1-11. [CrossRef]

18. Seleci, M.; Seleci, D.A.; Scheper, T.; Stahl, F. Theranostic Liposome-Nanoparticle Hybrids for Drug Delivery and Bioimaging. Int. J. Mol. Sci. 2017, 18, 1415. [CrossRef]

19. Cui, L.; Li, C.-C.; Tang, B.; Zhang, C.-Y. Advances in the integration of quantum dots with various nanomaterials for bio-medical and environmental applications. Analyst 2018, 143, 2469-2478. [CrossRef]

20. Porsiel, J.C.; Temel, B.; Schirmacher, A.; Buhr, E.; Garnweitner, G. Dimensional characterization of cadmium selenide nanocrystals via indirect Fourier transform evaluation of small-angle X-ray scattering data. Nano Res. 2019, 12, 2849-2857. [CrossRef]

21. Wang, F.; Shu, L.; Wang, J.; Pan, X.; Huang, R.; Lin, Y.; Cai, X. Perspectives on the Toxicology of Cadmium-based Quantum Dots. Curr. Drug Metab. 2013, 14, 847-856. [CrossRef]

22. Ulusoy, M.; Jonczyk, R.; Walter, J.-G.; Springer, S.; Lavrentieva, A.; Stahl, F.; Green, M.; Scheper, T. Aqueous Synthesis of PEGylated Quantum Dots with Increased Colloidal Stability and Reduced Cytotoxicity. Bioconjugate Chem. 2015, 27, 414-426. [CrossRef]

23. Wegner, K.D.; Dussert, F.; Truffier-Boutry, D.; Benayad, A.; Beal, D.; Mattera, L.; Ling, W.L.; Carrière, M.; Reiss, P. Influence of the Core/Shell Structure of Indium Phosphide Based Quantum Dots on Their Photostability and Cytotoxicity. Front. Chem. 2019, 7, 466. [CrossRef]

24. Ulusoy, M.; Walter, J.-G.; Lavrentieva, A.; Kretschmer, I.; Sandiford, L.; le Marois, A.; Bongartz, R.; Aliuos, P.; Suhling, K.; Stahl, F.; et al. One-pot aqueous synthesis of highly strained $\mathrm{CdTe} / \mathrm{CdS} / \mathrm{ZnS}$ nanocrystals and their interac-tions with cells. RSC Adv. 2015, 5, 7485-7494. [CrossRef]

25. Lin, G.; Ouyang, Q.; Hu, R.; Ding, Z.; Tian, J.; Yin, F.; Xu, G.; Chen, Q.; Wang, X.; Yong, K.-T. In vivo toxicity assessment of non-cadmium quantum dots in BALB/c mice. Nanomed. Nanotechnol. Biol. Med. 2015, 11, 341-350. [CrossRef]

26. Al-Jamal, W.T.; Al-Jamal, K.T.; Bomans, P.H.; Frederik, P.M.; Kostarelos, K. Functionalized-quantum-dot-liposome hy-brids as multimodal nanoparticles for cancer. Small 2008, 4, 1406-1415. [CrossRef] [PubMed]

27. Muthu, M.S.; Kulkarni, S.A.; Raju, A.; Feng, S.-S. Theranostic liposomes of TPGS coating for targeted co-delivery of docetaxel and quantum dots. Biomaterials 2012, 33, 3494-3501. [CrossRef] [PubMed] 
28. Gopalakrishnan, G.; Danelon, C.; Izewska, P.; Prummer, M.; Bolinger, P.-Y.; Geissbühler, I.; Demurtas, D.; Dubochet, J.; Vogel, H. Multifunctional Lipid/Quantum Dot Hybrid Nanocontainers for Controlled Targeting of Live Cells. Angew. Chem. Int. Ed. 2006, 45, 5478-5483. [CrossRef] [PubMed]

29. Demir, B.; Barlas, F.B.; Gumus, Z.P.; Unak, P.; Timur, S.; Demir, B. Theranostic Niosomes as a Promising Tool for Combined Therapy and Diagnosis: “All-in-One” Approach. ACS Appl. Nano Mater. 2018, 1, 2827-2835. [CrossRef]

30. Gao, X.; Zhai, M.; Guan, W.; Liu, J.; Liu, Z.; Damirin, A. Controllable Synthesis of a Smart Multifunctional Nanoscale Met-alOrganic Framework for Magnetic Resonance/Optical Imaging and Targeted Drug Delivery. ACS Appl. Mater. Interfaces 2017, 9, 3455-3462. [CrossRef]

31. Seleci, D.A.; Seleci, M.; Walter, J.-G.; Stahl, F.; Scheper, T. Niosomes as Nanoparticular Drug Carriers: Fundamentals and Recent Applications. J. Nanomater. 2016, 2016, 1-13. [CrossRef]

32. Xu, H.-L.; Yang, J.-J.; ZhuGe, D.-L.; Lin, M.-T.; Zhu, Q.-Y.; Jin, B.-H.; Tong, M.-Q.; Shen, B.-X.; Xiao, J.; Zhao, Y.-Z. Glio-maTargeted Delivery of a Theranostic Liposome Integrated with Quantum Dots, Superparamagnetic Iron Oxide, and Cilen-gitide for Dual-Imaging Guiding Cancer Surgery. Adv. Healthc. Mater. 2018, 7, e1701130. [CrossRef] [PubMed]

33. Muhamad, N.; Plengsuriyakarn, T.; Na-Bangchang, K. Application of active targeting nanoparticle delivery system for chemotherapeutic drugs and traditional/herbal medicines in cancer therapy: A systematic review. Int. J. Nanomed. 2018, 13, 3921-3935. [CrossRef]

34. Choudhury, H.; Pandey, M.; Chin, P.X.; Phang, Y.L.; Cheah, J.Y.; Ooi, S.C.; Mak, K.-K.; Pichika, M.R.; Kesharwani, P.; Hussain, Z.; et al. Transferrin receptors-targeting nanocarriers for efficient targeted delivery and transcytosis of drugs into the brain tumors: A review of recent advancements and emerging trends. Drug Deliv. Transl. Res. 2018, 8, 1545-1563. [CrossRef]

35. Calzolari, A.; LaRocca, L.M.; Deaglio, S.; Finisguerra, V.; Boe, A.; Raggi, C.; Ricci-Vitani, L.; Pierconti, F.; Malavasi, F.; De Maria, R.; et al. Transferrin Receptor 2 Is Frequently and Highly Expressed in Glioblastomas. Transl. Oncol. 2010, 3, 123-134. [CrossRef]

36. Kim, S.S.; Rait, A.; Rubab, F.; Rao, A.K.; Kiritsy, M.C.; Pirollo, K.F.; Wang, S.; Weiner, L.M.; Chang, E.H. The clinical po-tential of targeted nanomedicine: Delivering to cancer stem-like cells. Mol. Ther. 2014, 22, 278-291. [CrossRef] [PubMed]

37. Sonali; Singh, R.P.; Singh, N.; Sharma, G.; Vijayakumar, M.R.; Koch, B.; Singh, S.; Singh, U.; Dash, D.; Pandey, B.L.; et al. Transferrin liposomes of docetaxel for brain-targeted cancer applications: Formulation and brain theranostics. Drug Deliv. 2016, 23, 1261-1271. [CrossRef]

38. Jiang, W.; Xie, H.; Ghoorah, D.; Shang, Y.; Shi, H.; Liu, F.; Yang, X.; Xu, H. Conjugation of Functionalized SPIONs with Transferrin for Targeting and Imaging Brain Glial Tumors in Rat Model. PLoS ONE 2012, 7, e37376. [CrossRef]

39. Li, L.; Mak, K.; Leung, C.; Chan, K.; Chan, W.; Zhong, W.; Pong, P. Effect of synthesis conditions on the properties of citric-acid coated iron oxide nanoparticles. Microelectron. Eng. 2013, 110, 329-334. [CrossRef]

40. Masthoff, I.-C.; Kraken, M.; Menzel, D.; Litterst, F.J.; Garnweitner, G. Study of the growth of hydrophilic iron oxide nano-particles obtained via the non-aqueous sol-gel method. J. Sol Gel Sci. Technol. 2016, 77, 553-564. [CrossRef]

41. Sahoo, Y.; Goodarzi, A.; Swihart, M.T.; Ohulchanskyy, T.Y.; Kaur, N.; Furlani, A.E.P.; Prasad, P.N. Aqueous Ferrofluid of Magnetite Nanoparticles: Fluorescence Labeling and Magnetophoretic Control. J. Phys. Chem. B 2005, 109, 3879-3885. [CrossRef]

42. Maurer, V.; Altin, S.; Seleci, D.A.; Zarinwall, A.; Temel, B.; Vogt, P.M.; Strauß, S.; Stahl, F.; Scheper, T.; Bucan, V.; et al. In-Vitro Application of Magnetic Hybrid Niosomes: Targeted siRNA-Delivery for Enhanced Breast Cancer Therapy. Pharmaceutics 2021, 13, 394. [CrossRef]

43. Dufès, C.; Al Robaian, M.M.M.; Somani, S. Transferrin and the transferrin receptor for the targeted delivery of therapeutic agents to the brain and cancer cells. Ther. Deliv. 2013, 4, 629-640. [CrossRef]

44. Dixit, S.; Novak, T.; Miller, K.; Zhu, Y.; Kenney, M.E.; Broome, A.-M. Transferrin receptor-targeted theranostic gold nano-particles for photosensitizer delivery in brain tumors. Nanoscale 2015, 7, 1782-1790. [CrossRef]

45. Jhaveri, A.; Luther, E.; Torchilin, V. The effect of transferrin-targeted, resveratrol-loaded liposomes on neurosphere cultures ofglioblastoma: Implications for targeting tumour-initiating cells. J. Drug Target 2019, 27, 601-613. [CrossRef]

46. Sheykhzadeh, S.; Luo, M.; Peng, B.; White, J.; Abdalla, Y.; Tang, T.; Mäkilä, E.; Voelcker, N.H.; Tong, W.Y. Transfer-rin-targeted porous silicon nanoparticles reduce glioblastoma cell migration across tight extracellular space. Sci. Rep. 2020, 10, 2320. [CrossRef] [PubMed]

47. Devatha, G.; Roy, S.; Rao, A.; Mallick, A.; Basu, S.; Pillai, P.P. Electrostatically driven resonance energy transfer in "cationic" biocompatible indium phosphide quantum dots. Chem. Sci. 2017, 8, 3879-3884. [CrossRef]

48. Bi, Y.; Liu, L.; Lu, Y.; Sun, T.; Shen, C.; Chen, X.; Chen, Q.; An, S.; He, X.; Ruan, C.; et al. T7 Peptide-Functionalized PEG-PLGA Micelles Loaded with Carmustine for Targeting Therapy of Glioma. ACS Appl. Mater. Interfaces 2016, 8, 27465-27473. [CrossRef]

49. He, G.; Lin, W. Peptide-Functionalized Nanoparticles-Encapsulated Cyclin-Dependent Kinases Inhibitor Seliciclib in Transferrin Receptor Overexpressed Cancer Cells. Nanomaterials 2021, 11, 772. [CrossRef] [PubMed]

50. Wang, Y.; Xu, C.; Chang, Y.; Zhao, L.; Zhang, K.; Zhao, Y.; Gao, F.; Gao, X. Ultrasmall Superparamagnetic Iron Oxide Na-noparticle for T2-Weighted Magnetic Resonance Imaging. ACS Appl. Mater. Interfaces 2017, 9, 28959-28966. [CrossRef] [PubMed]

51. Khaniabadi, P.M.; Shahbazi-Gahrouei, D.; Jaafar, M.S.; Majid, A.M.S.A.; Khaniabadi, B.M.; Shahbazi-Gahrouei, S. Magnetic Iron Oxide Nanoparticles as T2 MR Imaging Contrast Agent for Detection of Breast Cancer (MCF-7) Cell. Avicenna J. Med. Biotechnol. 2017, 9, 181-188.

52. Sharma, A.; Baral, D.; Rawat, K.; Solanki, P.R.; Bohidar, H.B. Biocompatible capped iron oxide nanoparticles for Vibrio cholerae detection. Nanotechnology 2015, 26, 175302. [CrossRef] 
53. Ellis, M.A.; Grandinetti, G.; Fichter, K.M.; Fichter, K.M. Synthesis of Cd-free InP/ZnS Quantum Dots Suitable for Biomed-ical Applications. JoVE 2016, 108, e53684.

54. Ge, X.; Wei, M.; He, S.; Yuan, W. Advances of Non-Ionic Surfactant Vesicles (Niosomes) and Their Application in Drug Delivery. Pharmaceutics 2019, 11, 55. [CrossRef]

55. Saavedra-Alonso, S.; Zapata-Benavides, P.; Chavez-Escamilla, A.K.; Manilla-Muñoz, E.; Zamora-Avila, D.E.; Franco-Molina, M.A.; Rodríguez-Padilla, C. WT1 shRNA delivery using transferrin-conjugated PEG liposomes in an in vivo model of melanoma. Exp. Ther. Med. 2016, 12, 3778-3784. [CrossRef]

56. Balasubramanian, V.; Srinivasan, R.; Miskimins, R.; Sykes, A.G. A simple aza-crown ether containing an anthraquinone fluorophore for the selective detection of $\mathrm{Mg}(\mathrm{II})$ in living cells. Tetrahedron 2016, 72, 205-209. [CrossRef] 